\title{
Gaudi Dokunmamızı mı İstedi?
}

\author{
Yasemin ERKAN YAZICI ${ }^{1 *}$
}

Göz uzaklık ve ayrılığın, ten ise yakınlık ve içtenliğin organıdır. Görme ile uzaklar ve bina derinlikleri algılanabilirken, dokunma ile yakındaki şeylerin detayları anlaşılır...(Pallasmaa, 2011).

\section{ÖZ}

Bu makalede mimari mekanlarda dokunma duyusunu harekete geçiren etmenler ele alınmış, bu doğrultuda, Antoni Gaudi tarafından tasarlanan ve UNESCO Dünya Mirasları listesinde yer alan Sagrada Familia, Casa Mila, Casa Batllo yapıları ve Park Güel'deki giriş yapıları ve kemerli geçit incelenmiştir. İncelenen yapıların, iç ve dış mekan özellikleri, formları, malzemeleri, renkleri ve tasarımcının bu formları oluştururken ilham aldığı malzemeler ele alınmıştır. Ayrıca yapılan gözlemlerden yararlanılarak ziyaretçilerin dokunma duyusunun bu yapılar üzerindeki etkisine değinilmiştir.

Anahtar Kelimeler: Dokunma duyusu, yüzey dokusu, mekan, Gaudi

\section{Did Gaudi want us to Touch?}

\begin{abstract}
In this article, the factors that act on the sense of touch in architectural spaces are discussed.

The Sagrada Familia, Casa Mila and Casa Batllo buildings which are designed by Antoni Gaudi and listed on the UNESCO World Heritage list, and the entrance to the Park Güel and the arched passage were analyzed. Interior and exterior features, forms, materials, colors and materials inspired by the designer creating these forms are discussed of these structures Furthermore, These structure's effect's on tactile sensation have been investigated.
\end{abstract}

Key Words: Touch, surface texture, space, Gaudi

\footnotetext{
${ }^{1}$ İstanbul Kültür Üniversitesi, Mimarlık Fakültesi, Mimarlık Bölümü, yaseminerkanyazici@gmail.com *ilgili yazar / Corresponding author: Yasemin ERKAN YAZICI, y.erkanyazici@iku.edu.tr Gönderim Tarihi: 09.11.2016

Kabul Tarihi: 29.11.2016
} 


\section{Dokunulası Mekanlar}

Bazı yapılarda dokunma duyusu istem dışı harekete geçer, kişiyi dinlemez ve farkında olunmadan dokunulur.... Bu duruma ne neden oluyor. Neden dokunmak isteniyor? Bazı mekanlar dokunmak için mi tasarlanmış? Mimar dokunmamızı mı istedi? O zaman dokunalım...

Tüm duyular dokunma duyusunun uzantıları ve özelleşmiş halleridir. Buna görme duyusu da dahildir. Bu nedenle tüm duyusal deneyimler dokunma ile bağlantılıdır. Dokunma "Beden ile dünya arasında onu deneyimlemek için oluşan bir arayüz gibidir" (Pallasmaa, 2011).

Kişinin mekanı deneyimleme sırasında, bedensel ve zihinsel algıya bağlı olarak mekanla kurduğu etkileşim ve bütünleşme üzerinden kavranabilen dokunma olgusu, gözmerkezci paradigmadan farklı olarak, mimariyi anlamlandırmanın varlığına işaret etmektedir (Öktem Erkartal ve Ökem, 2015).

Mekanda bulunan objelerin ve mekanı oluşturan elemanların gözlemciden uzaklaşması, görüntünün yoğunluğunun aşamalı olarak değişmesine neden olmaktadır. Mesafelerin doğru algılanabilmesi için en önemli tamamlayıcı unsur dokunmadır. Bu doğuştan gelen bir özelliktir ve deneyimlere bağlı değildir (Gibson, 1986). Fransız filozof ve fenomenolog Maurice Merleau-Ponty (1968) dokunma ve görme arasındaki ilişkiyi "bakışlarla nesnelere dokunmak" olarak tanımlamıştır.

Antropolog Ashley Montagu'nun (1986) görüşüne göre; ten en eski ve en duyarlı organdır. Gözün üzerindeki ağ tabakasının üzerinde bile dönüşüme uğramış bir deri katmanı vardır. Dokunma bütün duyuların anasıdır ve diğer duyulara dönüşerek farklılaşmıştır. Pallasmaa'ya göre; ten mekanlardaki sıcaklık izlerini de inanılmaz bir şekilde takip eder. Bir ağacın altındaki gölge, güneşli bir alan, birer mekan ve yer deneyimine dönüşür. Bu makalede Antoni Gaudi tarafından tasarlanan ve UNESCO Dünya Mirasları listesinde yer alan (URL 1) Sagrada Familia, Casa Mila, Casa Batllo yapıları ve Park Güel'deki giriş yapıları ve kemerli geçit incelenmiştir. Özellikle incelenen yapılardaki formları oluştururken tasarımcının ilham aldığı malzemeler ve objeler ele alınmış, dokunma duyusunun bu yapılar üzerindeki etkisine değinilmiştir.

\section{Antoni Gaudi Hakkında Genel Bilgi}

Art Nouveau akımının öncüsü Katalan mimar Antoni Gaudi'nin (1852-1926) babası bir bakırcı ustasıdır. Gaudi çocukluğunda demirci çırağı olarak çalışmış ve bu konudaki yeteneğini yapılarına yansıtmıştır. Eserlerine genellikle Neo-Gotik ve Art Nouveau akımlarını yansıtan mimar, tüm eserlerinde doğadan esinlenmiştir. Ona göre doğada düz çizgi yoktur ve bu sebeple hiç bir eserinde düz çizgi kullanmamıştır. Eğer keskin hatlı çizgiler kullanacaksa bu tekdüzeliği bozmak için asimetriyi kullanır (URL 2). Genellikle coğrafi oluşumlardan, bitkilerden ve hayvanlardan ilham alan Gaudi, tasarımlarında dağ, yaprak, kuru dal, çiçek, meyve, bal peteği, iskelet ve kemiklerin formlarını kullanmıştır.

\section{Sagrada Familia}

Sagrada Familia'nın yapımına 1882'de mimar Francisco de Paula del Villar y Lozano tarafından başlanmıştır. 1883 yılında Gaudi devralmış ve 1926 yılında vefat edene kadar tasarımı ve yapımında bulunmuştur (Crippa, 2007). Yapının inşası Gaudi'nin tasarımları doğrultusunda halen devam etmektedir. 
Kapılardaki yaprak formuyla oluşturulan örüntülerde, iç mekandaki kolonların sanki ormanın içerisinde dolaşıyormuş gibi konumlanmasında (Şekil 1), mimar doğadan yapmış olduğu esintiyi başarılı bir şekilde yapıya yansıtmıştır.

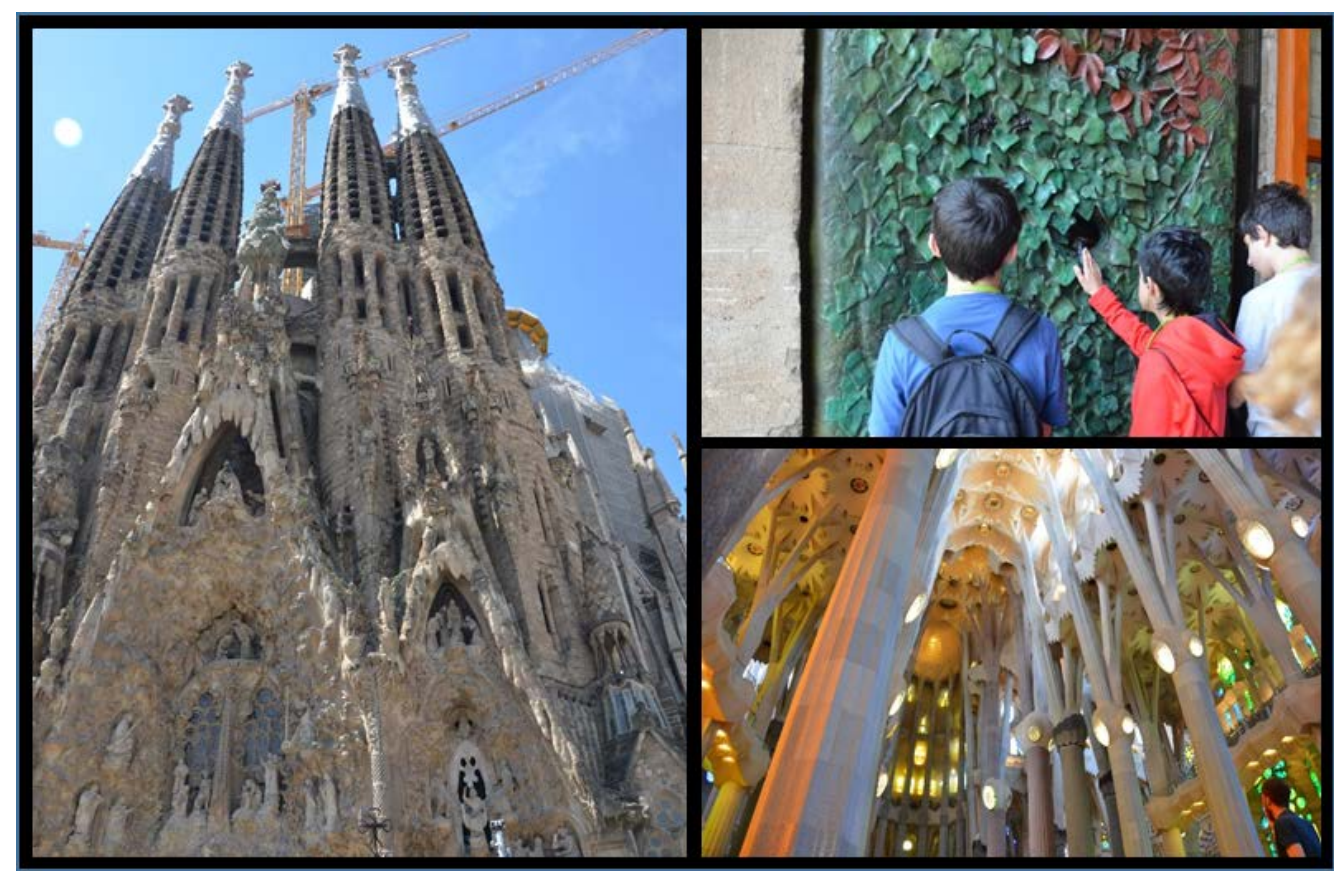

Şekil 1. Sagrada Familia'dan görseller (Çakıcı Alp ve Erkan Yazıcı arşivi, 2016)

Mekanla ilgili bilgiye ulaşmada, çok katmanlı mekan oluşumunu ifade eden deneyim algının yerini alır. Mekanı algılarken onunla bir ilişki kurulur. Kurulan ilişkide mekanın içselleştirildiği an mekansal deneyim oluşur (Aydınlı, 2009). Bu deneyim, mekanda geçirilen zaman miktarına göre farklılık gösterebilir. Sagrada Familia büyük ve çok fazla detay içeren bir yapıdır. Yapı hakkında kişide oluşacak mekansal deneyim, yapıda geçirilen süreye göre de farklılık gösterebilir. Yapılan gözlemlerde, süre farkı gözetmeksizin, ziyaretçilerin en çok Sagrada Familia'nın kapılarına ve kolonlarına dokunmaya çalıştıkları tespit edilmiştir.

\section{Casa Mila}

Casa Mila, 1905-1910 yılları arasında Gaudi tarafından tasarlanıp inşa edilmiştir. Mimar balkonları ve cephedeki her bir nişi (Şekil 2) birbirinden farklı deniz dalgası formunda tasarlamış, dökme demir balkon demirlerindeki yosun soyutlaması ile dalga efektinin daha güçlü bir biçimde algılanmasını sağlamıştır. (URL 3).

Yapının içinde bulunan iki avlu ile güneş ışığından olabildiğince faydalanılmaya çalışılmıştır. Çatısında yer alan her biri farklı tarzda tasarlanmış olan bacalar yapının en dikkat çekici özelliklerinden biridir (Şekil 2). Bu bacalar bakan kişiler tarafından farklı algılanmakta farklı hayali karakterlere benzetilmektedir. Yapılarında hayvan iskeletinden de esinlenen Gaudi Casa Mila'nın çatı arasındaki tonoz çatkısını yılan iskeleti formunda tasarlamıştır. 


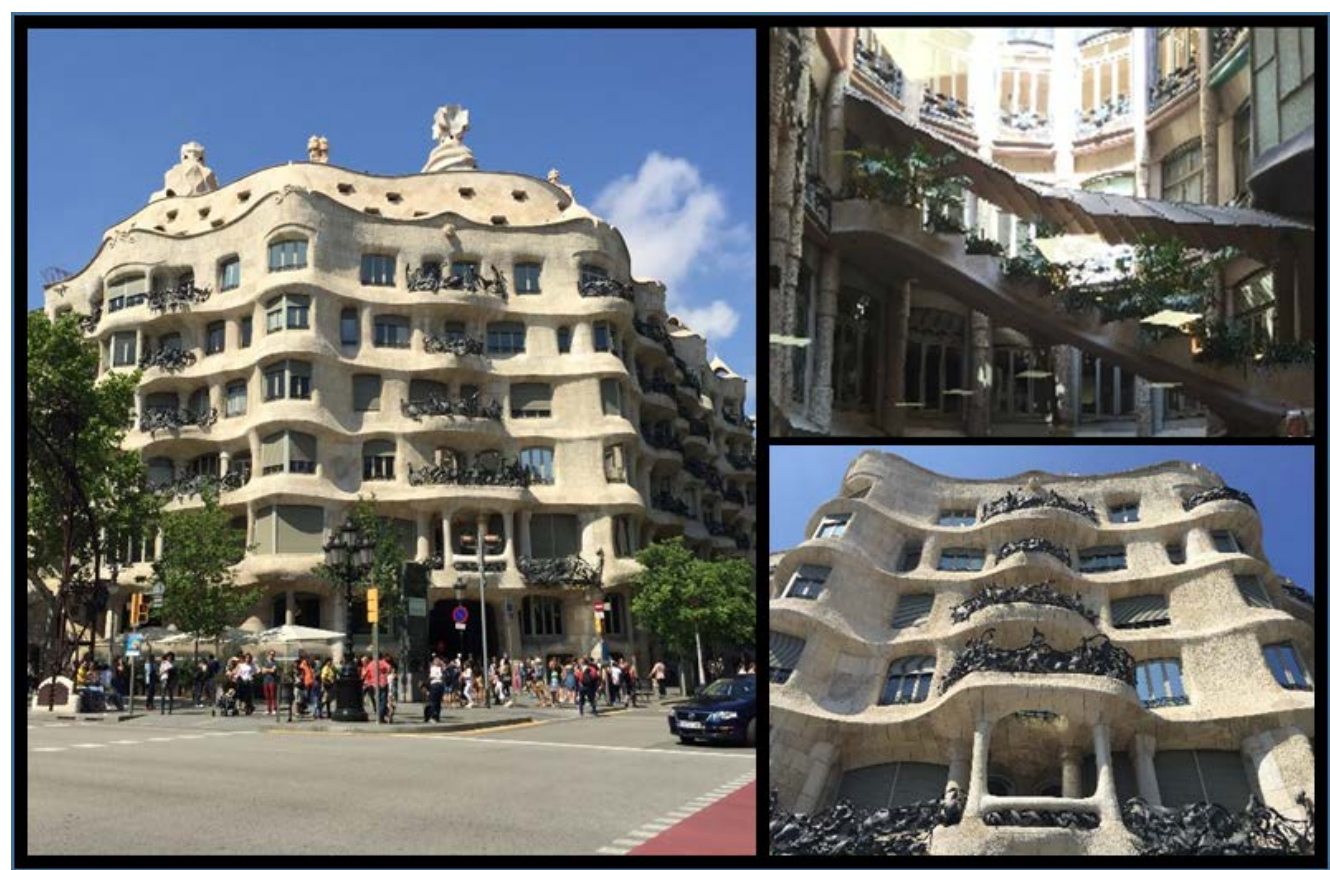

Şekil 2. Casa Mila'dan görseller (Çakıcı Alp ve Erkan Yazıcı arşivi, 2016)

Dokunma ile kişi, uzaktan bakmanın aksine, yabancı bir varlığı kendi bedeninde hissetmektedir. Bu, kişi ve nesne arasındaki sınırın yok olması durumu, Martin Heidegger'e (1971) göre bir varlığın görme mesafesindeki "nesne"den çıkarak, dokunma mesafesindeki "şey"e dönüşme durumudur. Yapılan gözlemlerde ziyaretçilerin en çok Casa Mila'nın çatısında bulunan bacalara dokunmaya çalıştıkları tespit edilmiştir.

\section{Casa Batllo}

Casa Batllo, 1877 yılında Gaudi tarafından tasarlanıp inşa edilmiş 1905- 1907 yılları arasında değişiklikler yapılarak bugünkü halini almıştır. Modern mimari örneklerinden olan binanın özellikle zemin katı, hem plan hem de dış görünüşü ile farklılık yaratmaktadır (URL 4).

Gaudi bu yapısında da düz çizgilerden kaçınmıştır. Dar uzun dikdörtgen bir parselin içine inşa edilen binanın neredeyse ne dış formunda ne de iç formunda düz çizgiler kullanılmamıştır. Ön cephenin büyük bir kısmı kırık seramiklerle kaplıdır ve simetrik olmayan bir şekilde döşenmiştir. Yapının balkonlarında kemik görünümlü sütunlar, üst katlarında ise kafatası görünümlü parçalar yer almaktadır. Sürüngen görünümündeki çatıyı kimileri dinazora, kimileri ise ejderhaya benzetmektedir (Şekil 3). 


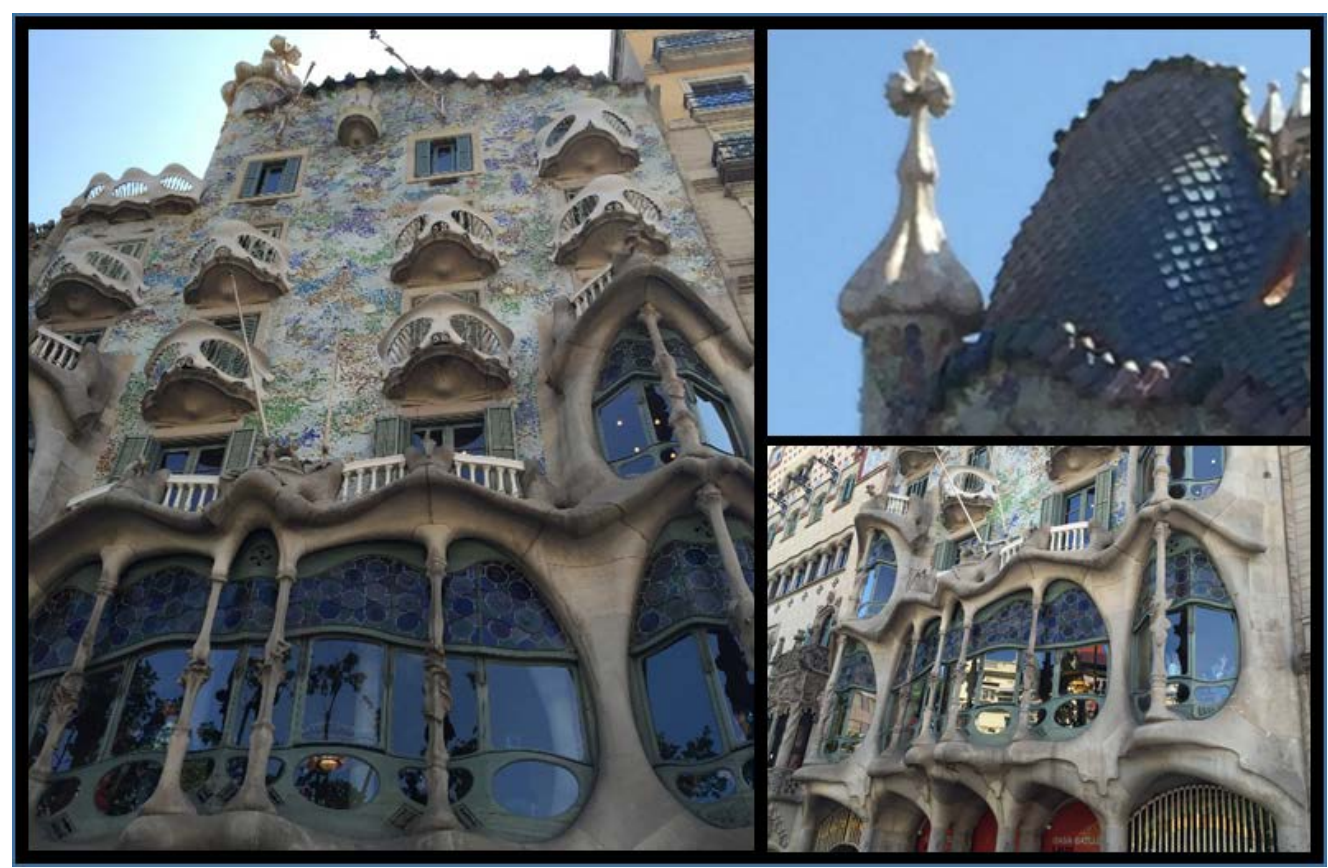

Şekil 3. Casa Batllo'dan görseller (Çakıcı Alp ve Erkan Yazıcı arşivi, 2016)

Yapıların yüzeylerini örten malzemenin dokusu mekanların derisini oluşturmaktadır. Bu deri kimi zaman pürüzlü, kimi zaman ise kaygan, şeffaf, mat, yumuşak ya da sert olabilmektedir. Tüm bu özellikler, Peter Zumthor'un (2006) söylemiyle "mimarinin vücut bulmuş halleri"dir. Casa Batllo'nun da ön cephesinde sanki yaşayan bir organizmanın derisi kaplıymış gibi görünmekte ve bu durum dokunma hissini uyandırmaktadır.

\section{Park Güell}

1900-1914 tarihleri arasında yapılan Park Güell, 1923'ten sonra halka açılmıştır. Parkın ana girişinde taştan yapılmış, mantarları anımsatan kubbe biçimli çatıları olan iki yapı bulunmaktadır (Şekil 4). Evlerin gerek cephesi gerekse iç mekanları eğik yüzeylerden oluşmaktadır. Ayrıca birinin çatısında iyiliği simgeleyen Aziz George Haçı, diğerinde ise kötülüğü simgeleyen zehirli mantar figürü bulunmaktadır. Renkli, kırık mozaiklerle oluşturulmuş cephelere sahip evleri gezenler kendilerini "Hansel-Gratel" ve "Alice Harikalar Diyarında" masallarının içindeymiş gibi hissetmektedir. 


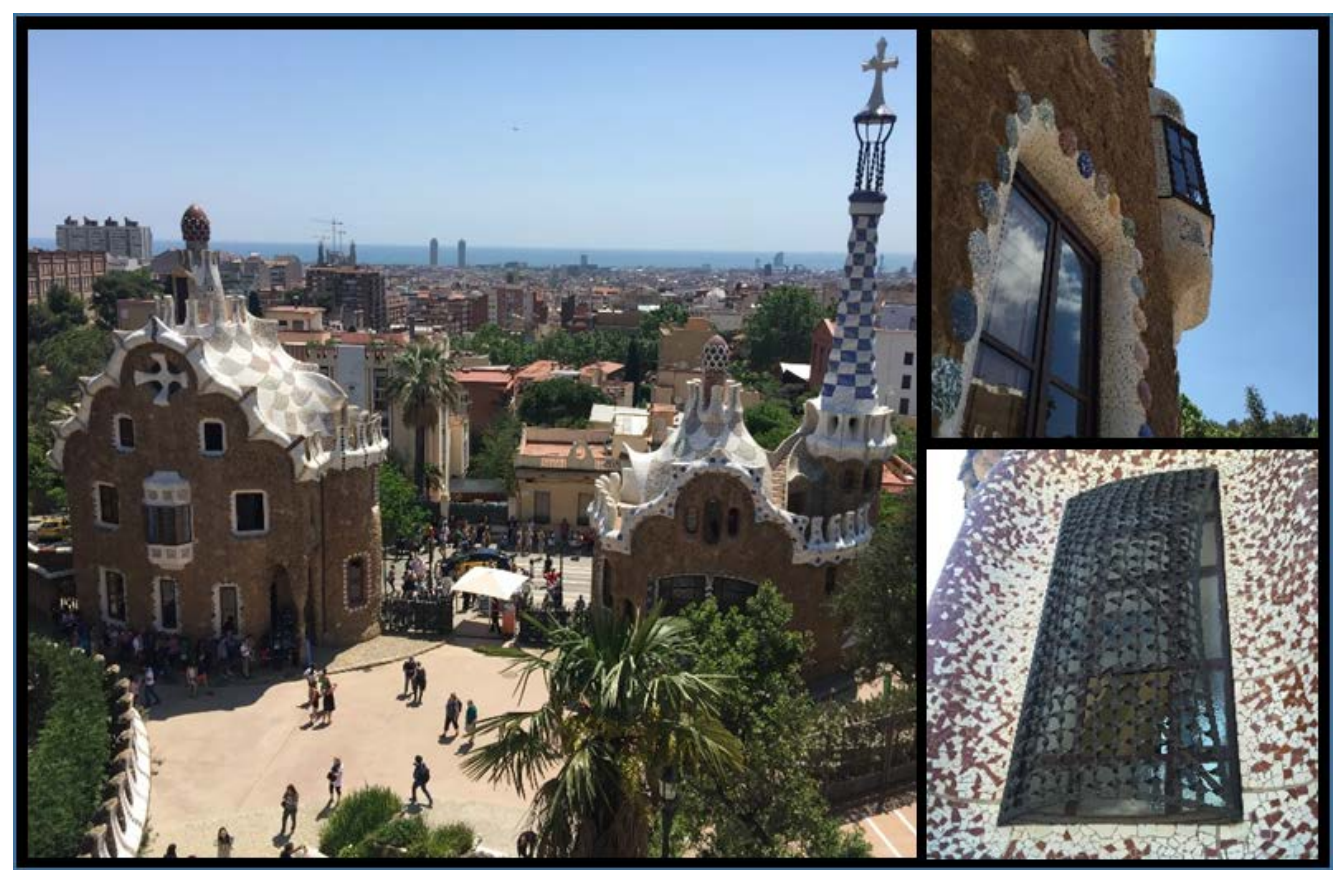

Şekil 4. Park Güell'in girişindeki iki evden görseller (Çakıcı Alp ve Erkan Yazıcı arşivi, 2016)

Heidegger'e (1971) göre eller düşüncenin organıdır. Dokunma duyusu bizi zaman içinde yolculuğa çıkarır ve geçmiş ile temasa geçmemizi sağlar. Park Güell'in girişinde bulunan iki ev de ziyaretçilere kendilerini sanki bu zamanda değilmiş gibi hissettirir. Evleri gezmek için oluşan sırada bile ziyaretçiler evin dış yüzeyine dokunmaya çalışmaktadır.

Eğimli araziye sahip parkta, ulaşımı kolaylaştırmak için, üç farklı seviyede kemerli geçitler oluşturulmuştur. Parktan çıkarılan taşlarla oluşturulmuş geçidin kolonları ve duvar yüzeyleri eğimlidir. Ayrıca şekli ve dokusu taştan çok ağaç gövdeleriyle oluşturulmuş hissi yaratmaktadır (Şekil 5).

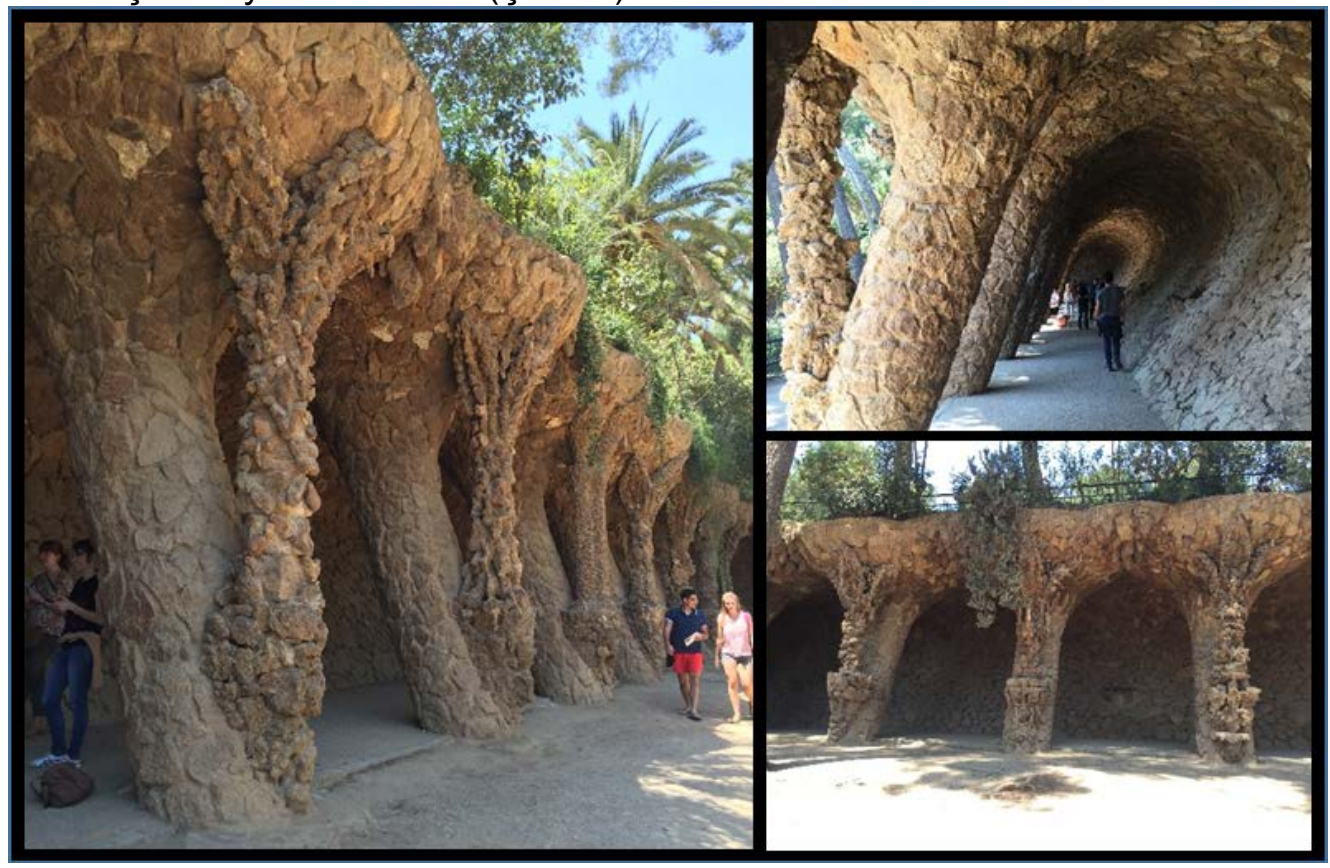

Şekil 5. Park Güell'deki kemerli geçitten görseller (Çakıcı Alp ve Erkan Yazıcı arşivi, 2016) 
İrlandalı filozof ve din adamı George Berkeley, dokunmayı görmeyle ilişkilendirmiş ve dokunma duyusunun işbirliği olmadan uzaklığın ve mekansal derinliğin görsel olarak algılanamayacağını belirtmiştir (Pallasmaa, 2011). Park Güell'deki kemerli geçitte bulunan sıra sıra kemerlerin de ne kadar mesafede olduğunu anlamak için bakmak yetmez, dokunma intiyacı hissedilir. Dokunarak sadece dokusu değil, aynı zamanda derinliği de algılanır.

\section{Sonuç}

$\mathrm{Bu}$ makalede Antoni Gaudi tarafından tasarlanan ve UNESCO Dünya Mirasları listesinde yer alan Sagrada Familia, Casa Mila, Casa Batllo yapıları ve Park Güel'deki giriş yapıları ve kemerli geçit incelenmiştir. Makalede özellikle incelenen yapılardaki formları oluştururken tasarımcının ilham aldığı malzemeler ve objeler ele alınmış, dokunma duyusunun bu yapılar üzerindeki etkisine değinilmiştir.

Antoni Gaudi tasarımlarında genellikle düz çizgi yerine, organik formlar kullanmıştır. Simetrinin tek düze olduğunu düşünüp, yapılarında asimetriye yer vermiştir. Bitki, hayvan ya da doğadan esinlendiği formları tasarımlarına yansıtmıştır. Her yapısında az ya da çok bu etki mutlaka vardır.

Dokunma duyusu, görme duyusu ile birlikte yüzeylerin dokularının daha net anlaşılmasını sağlamaktadır. Yüzeyin sert, yumuşak ya da pürüzlü olup olmadığını anlamak için görmek yetmez, dokunma intiyacı da hissedilir. Dokunma aynı zamanda mekanın derinliğini de daha iyi algılamamızı sağlamaktadır.

Yapılan gözlemlerde ziyaretçilerin genellikle Sagrada Familia'nın kapılarına ve kolonlarına, Casa Mila'nın bacalarına, Casa Batllo'nun kolonlarına ve yüzeylerine, Park Güel'deki giriş yapıları'nın yüzeylerine, Park Güel'deki kemerli geçitin kolonlarına ve yüzeylerine dokunduğu tespit edilmiştir.

Tüm bu tespitler sonucunda neden o yapı elemanlarına dokunuldu? sorusu akıllara gelebilir. Gerçekten de mimar o detaylara dokunmamızı mı istedi? Ona göre mi tasarladı?... Dokunulan yüzeylerin ortak özelliklerine bakıldığında; genellikle, aynı ortamdaki yüzeylerden daha dokulu ya da çoklu açılı olanlara dokunulduğu görülmektedir. Bu saptama, Gaudi'nin yapılarını dokunulmasını istediği yüzeyleri dikkate alarak tasarladığı şeklinde yorumlanabilir.

$\mathrm{Bu}$ araştırma sonuçları sadece gözlemin yapıldığı zamana ve o andaki ziyaretçilere aittir. Beden ve algı, kişiden kişiye hatta zamana göre farklılık gösterdiğinden, dokunma olgusunu sadece nesne odaklı değil, zaman ve kişiye göre değişen bir süreç olarak ele almak gerekir.

\section{Kaynakça}

Aydınlı, S., (2009) Mekandan Mekansal'a: Mekanın Zamansallığı/Zamanın Mekansallığı, Felsefe Ekibi Dergisi, 13.

Crippa, M. A., (2007) Gaudi, Taschen, Germany.

Gibson, J.J., (1986) The Ecological Approach to Visual Perception, Cornell University, Lawrence Erlbaum Associates, London. 
Heidegger, M., (1971) “The Thing”, 211-229; Poetry, Language, Thought, çev. A. Hofstadter, Harper \& Row, London.

Merleau Ponty, M., (1968) "The Visible and the Invisible: The Intertwining- The Chiasm", 247-272; Derleyen: Baldwin, T., (2004). Maurice Merleau Ponty Basic Writings, Routledge, USA.

Montagu, A., (1986) Touching: The Human Significance of the Skin, Harper\&Row, New York.

Öktem Erkartal, P. ve Ökem, H.S., (2015) Mimari Tasarımda Dokunma Olgusu ve Dokunsal Haritalamaya İlişkin Bir Alan Çalışması, Megaron, 10(1): 92-111.

Pallasmaa, J., (2011) Tenin Gözleri: Mimarlık ve Duyular, (çev) Kılıç, A.U.,YEM Yayınları, İstanbul.

Zumthor, P., (2006) Atmospheres: Architectural Environments-Surrounding Objects, Birkhäuser Architecture, Basel.

URL 1: World Heritage Centre. "Works of Antoni Gaudí". http://whc.unesco.org/en/list/320 (Son erişim tarihi: 11 Ekim 2016).

URL 2: National Geographic. "133 Years Later, Gaudí's Cathedral Nears Completion" (Aralık 2010) http://news.nationalgeographic.com/2015/11/151105-gaudisagrada-familia-barcelona-final-stage-construction/ (Son erişim tarihi: 20 Temmuz 2016).

URL 3: Mimdap. "Bir Dahinin Dokunuşuyla yapılmış heykel: CASA MiLA". (24 Temmuz 2012). http://www.mimdap.org/?p=94637 (Son erişim tarihi: 12 Ekim 2016).

URL 4: Mimdap. "Bir Gaudi harikası: Casa Batlló". (8 Kasım 2014). http://www.mimdap.org/?p=156621 (Son erişim tarihi: 18 Ekim 2016). 